\title{
Storage and Deposit Libraries
}

BY JERROLD ORNE

$\mathbf{I}^{\mathrm{T}}$ T IS MANIFESTLY IMPOSSIBLE to approach any single aspect of cooperative library effort without at least passing reference to the mass of literature gathered under the ample umbrella of cooperation. The bibliographical survey of John Rather $^{1}$ provides thorough documentation of most fields of cooperation up to 1955. Few additional references are needed to bring the listings up-to-date. In fact, in reviewing the literature, one is swiftly impressed by the constant recurrence of ideas conceived and expressed at very early dates in our library history. The essay of R. B. Downs ${ }^{2}$ in the printed report of the Monticello Conference of 1955, when combined with other discussion reports, provides a cogent statement of cooperation as we know it today. The problems are time-worn and well-known to all; solutions have been discussed for decades, with little progress made in practice. A few fields have made greater advances than others with signal, if not lasting, success. In technical processing, for example, the early production of printed catalog cards and their distribution has been an undeniable success. In acquisitions, the Farmington Plan has had only partial success at best. In spelling out resources, the development of the Union Catalog idea can certainly be credited with considerable success. Public service, in its normal growth, has developed cooperative plans on the local, state, and national level. Interlibrary loans and the free flow of materials where needed are hallmarks of our library systems.

1 "Library Cooperation," California Librarian, XVI (1955), 299-310.

2 "Library Cooperation and Specialization," in Prob. lems and Prospects of the Research Library, ed. by E. E. Willioms (New Brunswick, N. J.: Scarecrow Press, 1955).
Dr. Orne is Librarian, University of North Carolina. This paper is based on a longer study prepared for the Rutgers series on the State of the Library Art.

It is in the area of acquiring and organizing our material resources that the gravest problems not only continue but steadily increase as world production of the printed word grows. The difficulties of keeping up with the sum of knowledge expressed in printed form are not the first concern of this study, but problems of storage are so inter-related with those of acquisition that they can hardly be considered separately. In any case, solutions proposed and targets for research must involve both.

The scope of our consideration of deposit and storage libraries here will be limited to the philosophical or rational and, to a certain degree, the physical aspects of storage and deposit libraries. We are not concerned primarily with the library's contents although they provide the raison d'être and create the need for something other than standard library storage. We do not take up the equipment or equipping of storage buildings since this will be reported elsewhere and constitutes in itself a fairly complicated problem. The study will not consider storage planning in foreign libraries since their bases of operation are not comparable to ours and massive collections creating a need for storage are much less common abroad than in our country.

This study will be concerned with any factors compelling or contributing to the compelling need for storage facilities in 
any type of library and for any character of collection. It is inevitable that acquisition policies and collection programs must be given some consideration since they, in so great a measure, determine the need for extended storing areas. An effort will be made to isolate that part of theory of cooperation which affects massive growth of collections and to concentrate our attention on the physical entities which are storage libraries rather than their reason for being.

The storage library idea has attained its fullest development in the areas of the major public, academic, and special libraries. Every critical consideration of the storage idea has evolved primarily from problems of size. It follows normally then that the largest units are the most heavily involved. In fact, one might almost designate the need for a depository as a standard hallmark of attainment of size. Among the public libraries, the literature reveals only a few attacks upon the problem of storage by major public libraries. The public libraries of Providence, Denver, and Boston may be cited as leading examples. An extension of public library problems is found in reports on activities of some state libraries or state-wide groups of librarians in Indiana, California, and New Jersey. Their considerations are concerned on the one hand with providing central depositories to serve better a multitude of smaller units and on the other with attaining bibliographic control of a given state or region in order better to serve on a national scale. Major examples of the storage idea among the academic libraries include individual library solutions as well as joint or cooperative centers. The literature reveals few cases but reasonable variety among them. DePauw University, Iowa State College, the University of Michigan, the Hampshire Interlibrary Center, the Midwest Interlibrary Center, and the New England Deposit Library comprise the field. In addition to the state-wide plans briefly mentioned above, other examples of deposit and storage activities can be found on a very large scale in the federal government. Problems met by the Armed Forces Medical Library and the Library of Congress will serve to illustrate this point. Each of these has some bearing upon the growth and development of the idea of depository or storage libraries. When properly combined with considerations of the growth of collections and the availability of cooperative resources, it may be possible to establish a logical pattern for the development of deposit or storage libraries in our country.

Among the public libraries, and in terms of serving the general public of a given community or collection of communities, it is commonly recognized that the small public library in our country while it is often a well-funded, firmly established, and thoroughly accepted way of life, does not grow beyond the needs of its community or attain any great size. When the community involved is fairly large and its library correspondingly more complex, the possibility arises that an increasing proportion of the contents of this library is little used. One should expect this since size normally comes with age, and with age libraries tend to hold a larger proportion of out-of-date or historical materials. Together with age and size, one finds an increasingly complex system and greater difficulty in maintaining all materials and all services to all people.

Before considering the truly cooperative plans initiated by academic librarians or administrations, it should be mentioned that there have been individual library solutions to storage problems developed within numerous small, medium-sized and even large individual academic libraries. Although the literature reports few instances for the smaller and medium-sized libraries, there have been scores of cases where the growth of a small collection, even in the more modest 
institutions, has led to book storage in basements, attics, and classrooms, usually leading inevitably to the building of a larger library. It may be useful to cite a few examples recorded in the literature.

In 1945 the DePauw University Library was compelled to seek storage space outside of its building for a book collection which outgrew the library's space. ${ }^{3}$ A second instance of an individual academic storage plan was that of Iowa State College. ${ }^{4}$ In this case, a separate building at a distance from the library was constructed specifically for the purpose of providing cheap storage for library materials. The most recent and largest storage library for a single institution is the one which opened at the University of Michigan in February, 1956. These three examples are only illustrations of the tenor of thought and the stage of development the storage idea holds in some academic institutions. In fact, the same may be said for virtually all except a very few, very large universities. Almost any one of the librarians or administrators concerned will grant that his present solution is only a temporary one, but so far no one is willing to accept what has been done by cooperative effort as the final or best solution.

We do have one outstanding example of a cooperative plan which, on a small scale and involving a limited number of institutions, does accomplish some of the goals so frequently alleged for cooperative enterprise. The Hampshire Interlibrary Center ${ }^{5}$ was established at the end of 1951 as a joint enterprise of Amherst, Smith, and Mt. Holyoke. Although other institutions may elect membership, these three comprise the originators and continuing active participants. In this enterprise, there are three cooperating colleges within a five mile radius. Each

3 V. S. Cooper, "Depauw Library Storage Plan," Library Occurrent XVI (1948), 38-39.

* R. W. Orr and L. S. Thompson, "The Library Storage Building," Library Journal, LXVII (1942), $150-53$.

5 Flora Belle Ludington, "Hampshire Inter-Library Center," ALA Bulletin, XLVI (1952), 10-12. is a fairly sizeable and mature institution having sufficient support to develop collections beyond current use. The size of the collections stored is still sufficiently small so that any consideration of space used, present or proposed for the future, contemplates using space in existing buildings at some institution of the area. In effect, the Hampshire Interlibrary Center is a relatively small enterprise, organized within narow limits of geographical area and member institutions. Within these limits, it has been possible to experiment to the very considerable advantage of each of the institutions involved in terms of both costs and resources. The problems become infinitely more difficult and cannot hold the same pattern when the cooperating institutions are many, large, and varied and when the geographic area is multiplied ten times or a hundred times over.

An early account of the development of the New England Deposit Library ${ }^{6}$ alludes to the turn of the century statements of President Eliot and the controversy over "dead books" 7 and traces the development of the idea into a structure. Mr. Metcalf's reporting after thirteen years of use provides many facts and figures as well as data concerning actual use. One positive gain lies in the statement "Though it has saved money, the New England Deposit Library could hardly be considered successful if it had not also demonstrated that the inconvenience entailed in storing books at a distance from the main collection is not an unbearable burden on scholars." 8 It seems clear from the literature that the New England Deposit Library has provided essentially one basic advantage, that is, cheap storage.

The most extensive and widely publicized venture in cooperative storage up

6 K. D. Metcalf, "The New England Deposit Library," Library Quarterly, XII (1942), 622-28.

7 K. D. Elkins, "President Eliot and the Storage of "Dead, Books," Harvard Library Bulletin, VIII (1954), 299-312.

8 "The New England Deposit Library After Thirteen Years," Harvard Library Bulletin, VIII (1954), 317. 
to this time is the Midwest Interlibrary Center. The Center is a creature of the inventive imagination found among a number of prominent academic administrators and librarians. The initiative was taken by Colwell and Fussler at Chicago, Ellsworth at Iowa, and McDiarmid at Minnesota. ${ }^{9}$ The Carnegie Corporation provided most of the money to launch the enterprise $(\$ 750,000)$ and the Rockefeller Foundation added $\$ 250,000$ to provide an initial capital of one million dollars. The building which houses the Midwest Interlibrary Center was completed in 1951 at a cost of approximately $\$ 780,000$. It is located on the campus of the University of Chicago. The building is designed essentially as a storage warehouse for books with a minimum of space provided for public service and staff. Its capacity is reported to approach three million volumes. ${ }^{10}$ In a recent report of the Midwest Interlibrary Center, the former director summarizes six years of operations by the statement that "At least one important measure has been accomplished: member libraries have been relieved of congestion in their book stacks to the tune of more than $1,000,000$ volumes. .."11

No attempt to portray the development of the storage or deposit idea would be complete without some representation of the great special libraries found in Washington and their past and current problems. At least two major storage problems can be shown to demonstrate quite different types of problems and solutions.

In the first instance the motive was not need for more storage space, but need for more secure storage in wartime. Early in 1941, Mr. Archibald MacLeish became very concerned ${ }^{12}$ lest much of

- E. W. McDiarmid, A Midwest Inter-Library Center. [Chicago, 1948], $52 \mathrm{p}$.

${ }_{10}$ R. T. Esterquest, "Midwest Center," Library Journal, LXXVI (1951), 2031-35.

11 Midwest Inter-Library Center. Eighth Annual Re. port [Chicago, 1957], p. 17.

12 Jerrold Orne," "The Library of Congress: Prepares for Emergencies," ALA Bulletin, XXXV (1941), 341-48. the irreplaceable portion of the Library of Congress's collections might be destroyed by enemy attack. First consideration was given to bomb-proof shelter, dead storage, in the mountains of nearby Maryland. Fortunately, for U. S. finances, more mature thought led to a relatively painless and inexpensive series of depositories in existing libraries at a number of isolated but readily accessible locations. The thousands of books moved out of Washington for the duration ${ }^{13}$ were as completely available as the nearest telephone. At the end of the war, the collections were returned to Washington without untoward incident. This example is cited chiefly to suggest that all libraries are not always completely filled.

In this same period, yet another type of problem faced the Army Medical Library, now known as the National Library of Medicine. Crowded and miserably housed for decades, the situation in wartime made the danger to the old and rare collections of this great library an extremely grave problem. In July of 1942 , a junior member of the staff was sent to set up a part of the AML collections in rental space at the Allen Memorial Medical Library in Cleveland.14 All books published before 1800 were destined for the new depository, now the History of Medicine Division. This installation was not intended as a dead storage center; its materials have been in continuous active use since their installation, are fully cataloged, maintained and served when needed. Although this installation continues currently in the same space today, it will doubtless return to join its more modern counterparts of the nineteenth and twentieth centuries in the new building this national resource will soon build. In this instance, the storage motivation was both space and preservation; again the depository was at

13 Orne, Report on Precautionary Measures Regard. ing Its Collections Adopted by the Library of Congress (Washington: Library of Congress, 1941). 25 p. Mimeo. Washington: Library of Congress, 1941). 25 p. Mimeo.
16 Dorothy M. Schullian and F. B. Rogers, "The National Library of Medicine," Library Quarterly, XXVIII (1958), 113 . 
a very considerable distance. There are parallels or similarities to factors inherent in both the academic and public problems. The materials are of the "little-use" class. Preservation of unique copies is involved. Service at a distance and a time lag are present. Pressures of modern acquisition were compressing available space ever more. In short, the fundamental motivation toward deposit or storage libraries is basically the same in virtually every type of library we have discussed.

It is evident from the foregoing passing in review of a wide range of levels and types of library enterprises in the field of storage that the profession has striven manfully to cope with an ever-increasing flood tide of library materials. Yet we remain with the uneasy feeling that the whole thing has not come off, that such solutions as we have found to the present time are not within shouting distance of adequate. Downs, in a recent article $^{15}$ spells out a number of pros and cons for certain cooperative efforts, but has no panacea to offer. His plea is for the use of the scientific approach. He believes that we now have "an increasing number of leaders in our profession trained in research methods and experimental techniques," and goes on to say: "Let's start applying these criteria to plans for library cooperation, as well as to every other phase of professional librarianship. In other words, I am proposing that we use our heads rather than our hearts. This is the way to achieve a true profession." 16 With this admonition before us, perhaps we can expose the past record to thorough examination and find some useful guidance in what remains.

We first considered the public library. There is ample material in the record to demonstrate that the needs of the typical public library for storage are not the same as those of the monumental public,

15 "Realistic Considerations in Library Cooperation," Southeastern Librarian, IV (1954), 114-122, 138. 10 Ibid., p. $122,138$. academic, or research libraries. The public libraries have made considerable progress in theory, if not in practice, and their part of the solution has been fairly well documented. For the most part, public libraries would be amply served by the establishment of state-wide or, occasionally, regional depositories into which they could pour all of their littleused materials, to be weeded down to a single copy basis available to all comers. Each public library would then maintain a proper level of operating collection to serve its constituency and might thus change in size only as its constituency and their needs grew. In many cases, libraries of optimum size could result, with older and little needed books leaving by the back door in the same numbers as new and more live books entered the front. The exceptions to this rule among the public libraries would be the great old libraries of our principal cities whose collections must now be classed as research collections. These libraries might serve as a central depository or join resources with neighboring academic or private research libraries. The other alternative, using the state library agency as the central depository is the more usual approach in planning for this segment of our library economy. Let us bear in mind chiefly that each state, or group of states, has a fundamental responsibility for its own residents.

The small colleges and lesser universities (if there are any who will admit of this), almost in the same manner as their public library counterparts have a basic and standard set of needed resources which are common to all, fairly modest in extent, relatively slow to change. Again, it is quite possible to envisage an optimum size for the majority of such institutions, with stability attained by channeling the older and little-used materials out in numbers comparable to those of the new books entering the collection. The college library's discards might be combined with the public li- 
brary's in a nearby depository, except in unusual cases where national uniqueness may be in question. Special libraries, which are predominantly narrowly specialized by subject, are not concerned with problems of storage. Bibliographic co-ordination is the ultimate goal for them.

From a purely negative point of view, many types of libraries listed immediately above could do as well by destroying everything rejected as any other way. On the positive side, relegating all secondary materials to selective storage automatically assures the development of a total resource, slightly less available to be sure, but still available, beyond the fondest dreams of acquisitive librariantypes. Purely analytical consideration of the financial potential of these smaller libraries allows no illusions concerning their capacity for supporting, even in a small way, the establishment or the maintenance of a state or regional depository.

The approach to major public, research, and academic libraries on the subject of size and storage is quite another matter. Scholars and researchers, whether in our major public, academic, or research libraries are notoriously demanding and exigent; administrators of such institutions or their own administrations may be inordinately and unthinkingly ambitious; and the range of interests is as broad as life and changes like a kaleidoscope with each new twist. How then, can a library's activities be fixed long enough to determine what is needed, or should one seek to fix them at any time? The library must be ever responsive to current needs and its success is measured in direct proportion to its swift responsiveness. What we have then, when analyzed, is a type of institution which cannot be fixed or stable, one which can operate best when it is most free of trammeling anachronisms in materials, collections, or even services. On the other hand we have institutions whose current needs far exceed their ca- pacity to acquire, organize, and serve. We must therefore seek solutions for both elimination and addition, bearing always in mind the unspoken mandate to never reduce out any last copy of a potentially useful item.

The devices reported on here, even to the most highly developed, fall far short of attaining ultimate goals. We have had only a few partial efforts to resolve the growth problems, both in acquisition and in reduction. We do not have universal acceptance of what we have; on the contrary, we have to aggressively and studiously fight to continue even that. It seems that we must look elsewhere for solutions.

Much earlier in this study it was stated that acquisitions planning and storage planning could not be considered separately. It seems now even more accurate to say that any solutions to the problems of storage must consider input as well as output from our libraries. It also seems evident that certain elements of our present library philosophy are no longer tenable, and some of these are the very elements which have prevented earlier cooperative planning from attaining any durable progress. Two particular ideas require close and analytic examination before we can accomplish much in the two areas of our main interest. The first of these is the concept of responsibility for complete, global coverage and where it lies. The second is the concept of library property.

There are at least three and possibly five major libraries of this country which tacitly accept national responsibility for providing anything requested and which maintain library facilities to do this. These are, in order of decreasing readiness to publicly acknowledge this responsibility, the Library of Congress, Harvard University, Yale University, the University of California, and the University of Illinois. Note that only one of these is federal, two are private, and two are state institutions. It is now anachro- 
nistic for any one of these institutions to hold such a responsibility for its own, even the Library of Congress. It is not anachronistic, however, to entertain a new concept of national responsibility, with a nation-wide plan calculated to utilize every major and minor, private or public institution to the extent that it should participate in a national responsibility. Such a plan could be directed by the Library of Congress or even by some supra-national library authority. In the area of acquisitions, the entire output of world printing on a single copy basis could be funded by the government quite painlessly in large part by the free use of counterpart funds, and by direct appropriation in the interest of world trade where such funds are not available. The total annual sum needed to carry out such a plan would be less than the cost of one large missile, and unless we can attain national understanding and acceptance of the global bibliographic responsibility, there may not be much purpose in trying to push our rockets to the moon. The first essential change needed in library philosophy affects principally Acquisitions, and this is the complete understanding and acceptance of the national responsibility for acquisition on a global basis of the printed record.

Once this principle is established, the inflowing materials require our attention to the second, which then leads us to our prime subject, storage libraries. The second principle must be accepted not only by the national government, but also by every library of the country-and this is the principle of nation-wide ownership of library materials. This does not mean that any library can demand any other library's books. It does mean that any library may voluntarily turn in such books as it chooses to a national reserve, with the assurance that a copy will always be available for use in some library of this country. Incoming foreign materials under the national reserve plan would first be made available without cost to libraries which might elect to receive certain subjects and certain countries, precataloged at source and shipped direct. Those not requested would flow to preselected depositories to be established under state-federal plans. The same depository could serve public, academic and national purposes; the resources of each could be held to one copy of each, if necessary, and for the majority of all titles, this might well suffice. Single card reporting, to a national reserve card center could conceivably relieve fifty states of even their last copy of an unlikely item. Under such a system, as rapid communication and facsimile transmission reach a practical stage, the location of a unique copy in any part of our country would constitute no barrier to use. These ideas may seem visionary, but they do represent one possible approach to the resolution of a number of our toughest problems as well as a realistic view of what our ultimate goals must be. Whether or not it is possible to establish new principles now in our field, these suggestions will help to point up the targets for research which must be sighted in to prove or disprove our present theories.

We talk and write glibly on global acquisitions without any absolute proof that we need everything published anywhere or that everything published merits preservation. One field for critical investigation lies most certainly within this area. This kind of research implies also the determination of what is really needed in a given university library, a college library, or a public library, whatever its public. In brief, it demands scientific evidence of what a library needs in printed resources to do its job.

When we have the answers to what is needed, we will need research in methods of disposal, relocation, and reporting what is rejected. This involves critical examination of cataloging and decataloging methodology, transfer and storing (Continued on page 461) 


\section{Construction Data}

Architects:

Harold W. Burton \& Douglas W. Burton, associate.

Project cost:

$\$ 251,800.00$ for material costs. 55,000 hours of donated missionary labor valued at $\$ 125,000.00$.

Style of architecture:

Contemporary oriental influence.

Plan:

Designed on a $13^{\prime}-6^{\prime \prime}$ module.

Type of building according to code:

Class "A" type I fireproof structure.

\section{Wall construction:}

Concrete tilt-up wall construction.

\section{Floor construction:}

Earth bearing cement floors on main floor. Steel joist reinforced concrete slab on second story.

\section{Roof construction:}

Steel trusses $13^{\prime}-6^{\prime \prime}$ on center (module).

Roof:

Corrugated asbetos roof.
Windows:

Awning type aluminum.

Exterior doors:

Aluminum frame, glazed lights.

Ornamental trim:

Glass mosaic, ornamental aluminum and wrought iron.

Floor coverings:

Cork tile-rubber cove base.

Lighting:

Tubular fluorescent.

Wood trim:

Philippine wood glazed natural finish.

\section{Furniture:}

Hard rock maple with plastic tops.

Planning:

According to program issued by Kenneth T. Slack, Librarian of the Church College of Hawaii.

Architects fee:

$5 \%$ of the cost.

Total area of the building:

18,500 square feet which includes covered lanai and colonnade.

Storage and Deposit Libraries

(Continued from page 452)

problems, and the knotty difficulties of maintaining bibliographical control of widely scattered resources.

Some research in legal precedents will be required to enable interstate or even intra-state free relocation of library materials, but it seems quite likely that this concept will require new legislation rather than a review of past law. Research will be needed to demonstrate the importance of national responsibility, for this is one area where, with the exception of a few federal libraries, our country has developed very democratically a thoroughly dispersed national responsibility.
The above few indications of directions for research are not to be construed as implying that nothing has been done. However, we must recognize that it is far easier to find subjects needing research in our field, than areas where permanent solutions have been found. ${ }^{17}$ In the literature of storage and deposit libraries, despite its very considerable volume, we find only some germs of ideas, fundamentally sound, but insufficiently developed to obtain general acceptance in practice.

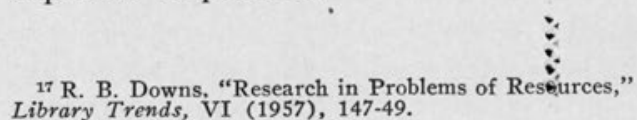

